\title{
Suicidal Phenol Ingestion: A case report
}

\author{
Ashish Tyagi ${ }^{1, *}$, Shashank Tyagi ${ }^{2}$, Nishtha Malik ${ }^{3}$, Hitesh Chawla ${ }^{4}$ \\ ${ }^{\mathbf{1}}$ Assistant Professor, ${ }^{\mathbf{4}}$ Associate Professor, SHKM Govt. Medical College, Nuh, Maharashtra, ${ }^{\mathbf{2}}$ Assistant Professor, Dept. of \\ Forensic Medicine, HBT Medical College \& Dr. RN Cooper Hospital, Juhu, Maharashtra, ${ }^{3}$ Resident, Dept. of Microbiology, \\ Govt. Medical College, Amritsar, Punjab \\ *Corresponding Author: \\ Email: djashtyg@yahoo.com,djashtag96@gmail.com
}

\begin{abstract}
Poisoning deaths is not an uncommon occurrence in India. Most frequent substance used for poisoning are agricultural poisons however use of corrosives for suicidal purpose was more frequent earlier. One of the most commonly used household and industrial corrosives is phenol. Atleast half of the phenol poisoning cases terminate fatally. The toxicological hazards of phenol and its derivatives must never be underestimated and mishandling of these substances can easily result in serious consequences. Phenol (carbolic acid) is one of the oldest and widely used antiseptic agents and being used in many commercially available products. We present here a case which demonstrates the potentially severe toxicity of suicidal ingestion of household phenol.
\end{abstract}

Keywords: Phenol poisoning, Suicide, Corrosives, Ingestion, Carbolic acid.

\section{Introduction}

Suicide is now among the three leading causes of death among those aged 15-44 years (both sexes). The rates of suicide among young people have been increasing to such an extent that they are now at the highest risk in a third of all developed/developing countries. ${ }^{(1)}$ Suicide by poisoning is among the most dramatic of all forms of suicide. Phenol is an organic corrosive acid. It is largely used as an antiseptic, as a disinfectant and a preservative. Phenol commercially is a brownish liquid containing impurities like cresol. Household phenol (often sold as phenyl) contains 5\% phenol in water. It has a characteristic, aromatic odour. ${ }^{(2)}$ Lysol is $50 \%$ solution of cresol in saponified vegetable oil and Phenol is about eight times more toxic than Lysol. ${ }^{(3)}$ Poisoning can occur by ingestion, inhalation and absorption through skin. Although many cases of phenol poisoning were reported in the past, acute oral overdoses of phenol containing solutions are relatively uncommon today. We present here such a case report of suicidal phenol ingestion which showed atypical autopsy finding of stomach.

\section{Case Report}

A 28-year-old male individual was brought to ENT OPD with alleged c/o of dysphagia and difficulty in speaking. On examination and subsequent perusal, the patient admitted that he had consumed phenyle (household toilet cleaner) one day earlier. On further examination, the patient was found to be hypotensive and tachypneic with bilateral constricted pupils. He was immediately admitted in the ICU, but after 4-5 hours he succumbed. The dead body was brought to the author for autopsy.

On external examination there were no external injuries marks present over the body. There was corrosion and greyish discoloration present at the angle of mouth and inner aspect of lips. On internal examination, the tongue was white and swollen. Mucous membrane of oral cavity was also sodden with ash gray discoloration. The mucosa of the oesophagus was tough and grayish-white (Fig. 1). Mucosa of the stomach was softened, blackened, tarry, corroded, grossly hemorrhagic, ulcerated and congested (Fig. 2) as compared to typical feature of phenol ingestion cases where the stomach inner surface is brown and leathery with hemorrhagic spots, corrugated and prominent rugae. All internal organs were congested. The stomach contained about $100 \mathrm{ml}$ of phenol odor emitting fluid. The entire peritoneum along with small and large intestine found to be congested and discolored (Fig. 3). During autopsy, viscera and different samples were preserved for toxicological examination. Histopathological examination showed exfoliation of oesophageal mucosa and coagulative necrosis of gastric mucosa along with features of glomerular congestion and acute tubular necrosis in kidney, congested and oedematous lungs and congested brain. The chemical analysis of routine viscera reports showed presence of phenol. The cause of death was opined as death due to acute tubular necrosis following phenol poisoning.

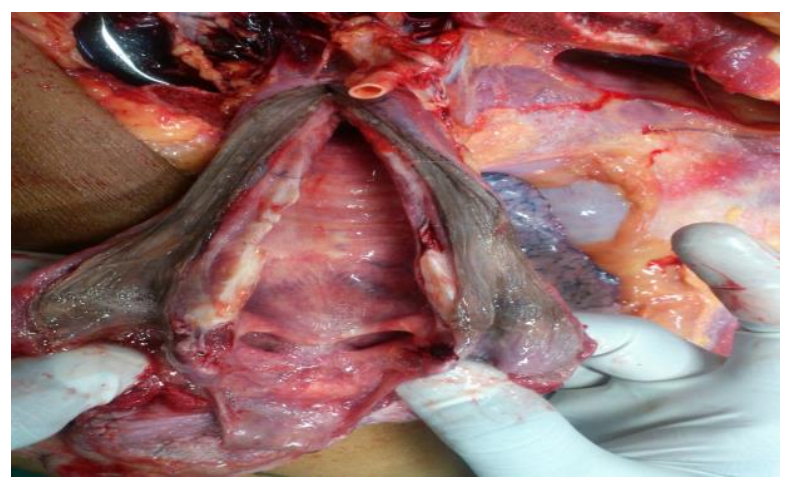

Fig. 1: greyish white discoloration of oesophagus inner surface 


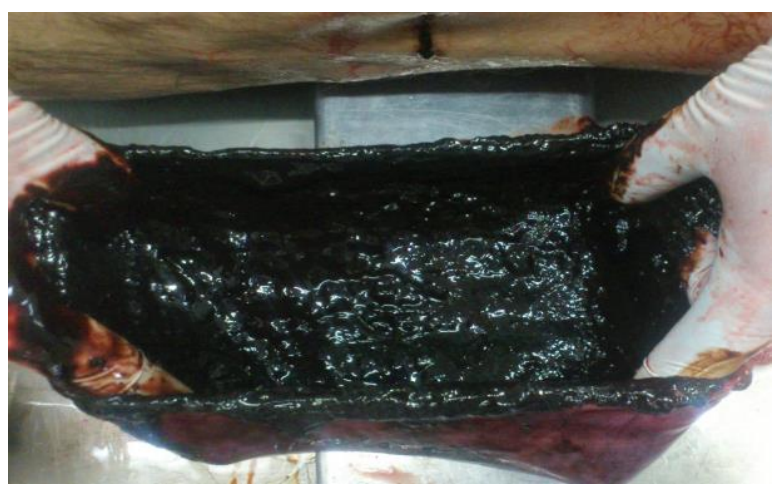

Fig. 2: inner mucosal surface of stomach showing corrosive effects of phenol

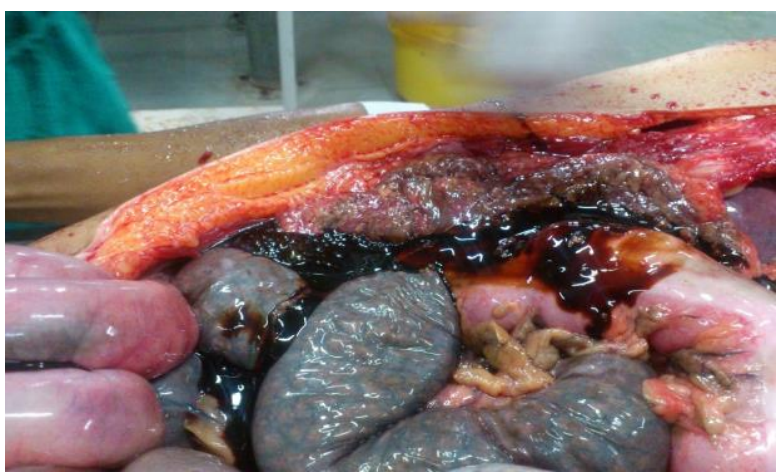

Fig. 3: small and large intestinal coils showing gross congestion \& discoloration

\section{Discussion}

Poisoning by carbolic acid is called as carbolism. It is a protoplasmic poison. It acts locally as a corrosive and after absorbing it exerts its central narcotic effect, affecting the medullary centres and higher centres, producing rapid loss of consciousness of the victim and profound collapse. ${ }^{(4)}$ Probable oral lethal dose is 50-500 $\mathrm{mcg} / \mathrm{kg}$. 25 to $50 \mathrm{ml}$ of household phenol can cause death in few hours to days. ${ }^{(2)}$

Phenol is readily absorbed and widely distributed following inhalation, oral, and dermal exposure (24hour urinary recovery of $85-95 \%) .{ }^{(5)}$ The major sites of metabolism are gastrointestinal tract, lungs, liver, and kidney. ${ }^{(5)}$ Intense burning of the mouth and throat may occur following swallowing a significant concentrated dose of phenol, leading to necrosis of the skin and mucous membranes of the throat, as well as abdominal pain and gastrointestinal irritation, nausea, vomiting, sweating, and diarrhoea. Phenol is considered to be very toxic to humans through oral exposure. Ingestion of $1 \mathrm{~g}$ phenol is reported to be lethal with symptoms, including muscle weakness and tremors, loss of coordination, paralysis, convulsions, coma, and respiratory arrest. ${ }^{(6)}$ Phenol has toxic effects on various organ systems such as cardiac, respiratory, renal, and the central nervous system. ${ }^{(7)}$ Phenol and its metabolites are predominantly excreted in urine as glucouronides and sulfates. The effects on kidney include darkening of urine, glucosuria, renal proximal tubule, and glomerular injury. ${ }^{(8)}$ Systemic manifestation includes central nervous system causing CNS depression, seizure, lethargy and coma and cardio vascular system like arrhythmias and hypotension. Metabolic acidosis, methhemoglobinemia, hypothermia also can get manifested. Phenol causes skin necrosis as it reacts with amino acids contained in the keratin and collagen of skin and leads to brown discoloration of skin and white patches in the oral cavity as seen in this case. ${ }^{(9)}$ Phenol levels in urine and blood can get elevated following ingestion and skin exposure and give a greenish blue color. ${ }^{(10)}$

The toxicity of conjugated forms of phenol is less than that of free compounds. Therefore, the free phenol concentrations in the blood can be regarded as an index of poisoning. ${ }^{(11)}$ Death is due to syncope and asphyxia due to (a) failure of respiration, (b) oedema of glottis, (c) complications. ${ }^{(3)}$

\section{Conclusion}

Carbolic acid is largely used as an antiseptic, disinfectant and preservative. Because of its large scale industrial and household use it is easily procurable, several cases of accidental and suicidal poisoning by carbolic acid have occurred. Use of carbolic acid for suicidal purposes is uncommon, though it is not rare. Poisoning with phenolic derivatives causes similar but less severe manifestations, and must be treated on same line as phenol.

\section{References}

1. Suicide prevention. World Health Organization. Available from:

<http://www.who.int/mental_health/prevention/suicide/su icideprevent/en/index.html >.

2. Pillay VV. Comprehensive medical toxicology. $2^{\text {nd }} e d$. Paras Publications: Hyderabad; 2008. 80-2.

3. Reddy K S N. The essentials of forensic medicine and toxicology. $30^{\text {th }}$ ed. Hyderabad: $2011 ;$ p.488.

4. Karmakar RN, editor. J.B. Mukharjee's Forensic Medicine and Toxicology. $4^{\text {th }}$ ed. Academic publishers: Kolkata; 2007.p.810.

5. Cassidy MK, Houston JB. In vivo capacity of hepatic and extrahepatic enzymes to conjugate phenol. Drug Metab Dispos 1984; 12(5):619-624.

6. Agency for Toxic Substances and Disease Registry (ATSDR), Toxicological Profile for Phenol, US Public Health Service, US Department of health and human services, Atlanta, GA, 1989.

7. Bruce RM, Santodonato J, Neal MW. Summary review of the health effects associated with phenol. Toxicol Ind Health 1987; 3(4):535-568.

8. Merliss RR. Phenol marasmus. J Occup Med 1972;14(1):55-56.

9. Michałowicz J, Duda W. Phenols - sources and toxicity. Polish Journal of Environmental Studies. 2007;16(3):34762.

10. Bentur Y, Shoshani O, Tabak A, Binnun A, Ramon Y, Ulman Y, Berger Y, Nachlieli T, Peled YJ. Prolonged elimination half-life of phenol after dermal exposure. Journal of Toxicology: Clinical Toxicology. 1998;36(7):707-11.

11. Boatto G, Nieddu M, Carta A, Pau A, Lorenzoni S, Manconi $\mathrm{P}$, et al. Determination of phenol and o-cresol by GC/MS in a fatal poisoning case. Forensic science international. 2004;139(2):191-4. 